\title{
La jurisprudencia del Tribunal Constitucional chileno sobre tratados internacionales: el específico caso de las cláusulas autoejecutables y no autoejecutables**
}

\section{The Jurisprudence of the Chilean Constitutional Court about International Treaties: The Specific Case of Self- executing and Non-self-executing Clauses}

\author{
RESUMEN
}

El presente trabajo se pronuncia sobre el tratamiento específico que ha dado la magistratura constitucional chilena a la cuestión de las cláusulas autoejecutables y no autoejecutables de los tratados internacionales, y sobre si dicho tratamiento es adecuado conforme al sistema constitucional de incorporación y vigencia del derecho convencional internacional en el ordenamiento jurídico nacional.

* Egresado de Derecho en la Universidad de Talca (Chile), cursó parte de sus estudios de pregrado en la Universidad de Valencia (España). Director de la revista Estudios Jurídicos Democracia y Justicia. Ayudante de los cursos de Derecho Internacional Público en la Universidad de Talca.Contacto: manuelyanez@outlook.es

El autor agradece a la Dra. Liliana Galdámez Zelada por su continuo apoyo para el desarrollo de su labor investigativa y los comentarios realizados a este trabajo. También agradece al Dr. Mauricio Baquero por la revisión del texto. Ambas lecturas críticas permitieron mejorar su original desarrollo. Cualquier error u omisión es responsabilidad del autor, así como las opiniones aquí expresadas.

** Este artículo es parte del proyecto de investigación Fondecyt de Iniciación 2015 n. ${ }^{\circ}$ 11150054 titulado "Los principios in dubio pro natura y de prevención en la actuación de los entes reguladores. El caso de la Comisión Nacional de Energía", cuyo investigador responsable es el Dr. Alberto Olivares Gallardo y donde el autor es asistente de investigación contratado.

Recibido el 12 de mayo de 2016, aprobado el 1. ${ }^{\circ}$ de octubre de 2016.

Para citar el artículo: M. YÁÑEZ EsPINOZA. La jurisprudencia del Tribunal Constitucional chileno sobre tratados internacionales: el específico caso de las cláusulas autoejecutables y no autoejecutables. Derecho del Estado n. ${ }^{\circ} 37$, Universidad Externado de Colombia, julio-diciembre de 2016, pp. 229-254. Dor: http://dx.doi.org/10.18601/01229893.n37.08 
PALABRAS CLAVE

Tribunal Constitucional, Chile, Tratados internacionales, cláusulas autoejecutables, cláusulas no autoejecutables.

\section{ABSTRACT}

This paper deals with the specific treatment that has given the Constitutional Court of Chile on the question of self-executing and non-self-executing provisions of international treaties, and whether the treatment is appropriate under the constitutional system of incorporation and validity of international treaties in national law.

\section{KEYWORDS}

Constitucional Court, Chile, international treaties, self-executing provisions, non-self-executing provisions.

\section{SUMARIO}

Introducción. I. El tema en cuestión. 1. El marco constitucional de los tratados internacionales en Chile. 2. La importancia de las cláusulas autoejecutables y no autoejecutables en Chile. II. La jurisprudencia del Tribunal Constitucional sobre tratados internacionales. 1. El Tribunal Constitucional chileno y los tratados internacionales. 2. Las cláusulas autoejecutables y no autoejecutables en el Tribunal Constitucional. III. Las cláusulas autoejecutables y no autoejecutables en Chile. 1. Conceptos y aclaraciones previas. 2. Procedencia de la distinción en nuestro sistema jurídico de la categoría autoejecutable/ no autoejecutable del derecho convencional internacional en su vigencia en el derecho interno. Conclusiones. Referencias.

\section{INTRODUCCIÓN}

El Tribunal Constitucional de Chile es el órgano constituido de cierre en la interpretación de la Constitución ${ }^{1}$. En sus más de treinta años de funcionamien-

1 Se ha sostenido: "son las Constituciones las que dotan al juez constitucional de la misión de guardián de la supremacía, integridad y fuerza normativa efectiva de la Carta Fundamental, otorgándole instrumentos como la declaración de inconstitucionalidad. En esta labor, corresponde a los tribunales constitucionales, a través de sus sentencias, determinar el sentido y alcance tanto de valores como de principios constitucionales que precisen el contenido y alcance de la normatividad infraconstitucional, desarrollando una labor integradora del derecho. Pero, también deben hacer un esfuerzo para desarrollar el principio de conservación de las normas 
to, el referido tribunal ha debido dotar de sentido y alcance a la Constitución en su aplicación. En su jurisprudencia el Tribunal ha tenido que enfrentar diversos dilemas, siempre haciendo efectiva la Constitución Política (CP) en la realidad ${ }^{2}$.

Producto de lo complejo de nuestro sistema de control de constitucionalidad, y en especial a partir de 2005 , esto es, luego de la reforma constitucional, el Tribunal ha variado constantemente sus criterios. Las principales razones para ello se encuentran en la naturaleza de una de sus principales atribuciones: el recurso de inaplicabilidad por inconstitucionalidad, y en la falta de una cultura jurídica del precedente en nuestro país, en el sentido de que ni cultural ni jurídicamente el Tribunal está obligado por su propia jurisprudencia ${ }^{3}$.

Hoy, en diversas materias, el Tribunal Constitucional no tiene una doctrina estable, lo que ha dado origen a conflictos interpretativos e incerteza jurídica. Entre ellos, el consistente en que el estatuto de los tratados internacionales en el sistema constitucional ha estado a fuego vivo desde los orígenes de la jurisprudencia del Tribunal, donde nunca ha existido claridad al respecto.

En esa materia se encuentra la categoría de cláusulas autoejecutables y no autoejecutables en los tratados internacionales que el Tribunal Constitucional incorpora a partir de la sentencia Rol n. ${ }^{\circ} 309$, y desde ahí, con diversas modificaciones, se sostiene hasta los roles acumulados n. ${ }^{\circ} 2387$ y n..$^{\circ} 2388$.

Dicha categoría, en un principio, no significó un gran problema, pero luego de las variaciones introducidas por el propio Tribunal derivó en problemática. El Tribunal no ha sido consecuente en su doctrina, con lo que ha generado incerteza y serios problemas en la aplicación del derecho, teniendo presente que el Tribunal Constitucional es el máximo órgano de interpretación de la Constitución ${ }^{4}$ dentro del ordenamiento jurídico chileno.

legislativas producto del Parlamento y otorgar al máximo la certeza del derecho que integra el ordenamiento jurídico, además de evitar los vacíos normativos y evaluar las consecuencias de sus fallos": VARGAS, 2011, p. 18.

2 Así en sus recientes fallos al pronunciarse sobre la jurisdicción militar (Tribunal Constitucional de Chile, Rol n. ${ }^{\circ}$ 2492-13, de 16 de junio de 2013), sobre la institución del Solve et repete (Tribunal Constitucional de Chile, Rol n. ${ }^{\circ}$ 1580-09, de 27 de enero de 2011), al declarar la inconstitucionalidad del artículo 38 ter de la Ley de Isapres (Tribunal Constitucional de Chile, Rol n. ${ }^{\circ}$ 1710-10, de 6 de agosto de 2010), al declarar la inconstitucionalidad de la delegación de facultades jurisdiccionales en sede tributaria (Tribunal Constitucional de Chile, Rol n. ${ }^{\circ}$ 681-07, de 6 de marzo de 2007), al resolver sobre la constitucionalidad del artículo 102 CC (Tribunal Constitucional de Chile, Rol n. ${ }^{\circ} 1811-11$, de 28 de abril de 2011), y sin dejar de mencionar las primeras sentencias del Tribunal que se pronunciaron sobre las leyes orgánicas constitucionales que dictó la Junta de Gobierno en el azaroso restablecimiento de la democracia en Chile. Todo ello, sumado a la juventud de nuestra judicatura constitucional, ha definido en muchos aspectos un sólido camino en la construcción del Estado de derecho en nuestro país; evidentemente, como en toda obra humana, la perfección es imposible, y el tema que trata este artículo es uno de esos aspectos criticables del Tribunal.

3 Sobre la cuestión del precedente véase ZuÑIGa, 2006.

4 Ibíd., 169. 
En términos introductorios, una cláusula de un tratado internacional es autoejecutable cuando es normativamente autosuficiente para ingresar al ordenamiento jurídico y ser aplicada por el operador jurídico nacional, en especial, la judicatura ordinaria. Viceversa, no es autoejecutable cuando no es autosuficiente. Esto es lo que ha sostenido en el Tribunal en su jurisprudencia ${ }^{5}$.

En tal perspectiva, este trabajo sostiene una hipótesis crítica respecto de la jurisprudencia constitucional en la materia, en lo que hasta aquí hemos denominado categoría de cláusulas autoejecutables y no autoejecutables de un tratado internacional en su vigencia en el ordenamiento jurídico interno.

La hipótesis planteada es la siguiente: conforme al sistema constitucional chileno, los tratados internacionales, una vez suscritos, ratificados y publicados, pasan a formar parte del ordenamiento jurídico interno como preceptos legales, y como tales, no admiten distinciones de aplicación por el operador jurídico nacional.

Desde el punto de vista metodológico, hemos seguido el método propio de las ciencias jurídicas, y hemos contrastado la hipótesis con la tradición constitucional chilena establecida en: su propio texto constitucional, la reiterada jurisprudencia de los tribunales ordinarios de justicia y la doctrina más relevante en Chile.

\section{EL TEMA EN CUESTIÓN}

\section{El marco constitucional de los tratados internacionales en Chile}

La Constitución chilena, luego de la reforma constitucional de 2005, incorporó mejoras en torno a la regulación del derecho internacional y su relación con el derecho interno. Recordemos que son los Estados quienes determinan la aplicación del derecho internacional en su sistema jurídico, conforme lo que señala Ximena Fuentes al respecto: "ni siquiera existe la obligación general de hacer que el derecho internacional ingrese al derecho interno" ". En este sentido, es la Constitución del Estado la que determina la recepción, vigencia, jerarquía y aplicación del derecho internacional en un país determinado, inclusive los tratados internacionales? ${ }^{7}$.

La Constitución Política de la República de Chile es deficitaria en la regulación de los tratados internacionales; en este sentido encontramos en la Ley Fundamental las siguientes regulaciones: de distribución competen-

5 PFEFFER, 2003, 479.

6 FuENTES, 2007, 3.

7 En el mismo sentido Medina, 1996, 53. Henríquez, por su parte, señala: "la Constitución de un Estado puede regular los requisitos necesarios para la celebración de un tratado, la determinación de los sujetos autorizados para hacerlo, los procedimientos que han de observar en su actuación y el modo de incorporar los tratados al ordenamiento interno": HeNRíQuez, 2009, 43. 
cial $^{8}$, de control de constitucionalidad ${ }^{9}$ y de incorporación de los tratados internacionales ${ }^{10}$.

En este contexto el Tribunal Constitucional opera frente a normas que resultan insuficientes en su labor, destacando que:

- La Constitución no regula la jerarquía de los tratados internacionales en el ordenamiento interno.

- La Constitución no regula de forma expresa los efectos de los tratados internacionales en el ordenamiento jurídico interno.

\section{La importancia de las cláusulas autoejecutables y no autoejecutables en Chile}

La cuestión de las normas autoejecutables y no autoejecutables deviene relevante en nuestro sistema de fuentes del derecho de forma evidente, frente a la crisis planteada respecto de la jerarquía normativa y los efectos de los tratados internacionales en nuestro ordenamiento. Considerar válida la teoría sostenida por el Tribunal sobre cláusulas autoejecutables y no autoejecutables en tratados internacionales implica dejar a merced de los operadores jurídicos internos el reconocimiento de los derechos subjetivos consagrados por aquellos en favor de las personas.

Por ende, plantearse la cuestión de la distinción entre cláusulas autoejecutables y no autoejecutables resulta crucial para la interpretación coherente del ordenamiento jurídico, así como para no incoar arbitrariedades en la determinación de los derechos que tienen las personas en Chile.

En esa perspectiva, a continuación se revisa la jurisprudencia del Tribunal Constitucional sobre tratados internacionales en cuanto fuente del derecho constitucional, para evidenciar la crisis presentada párrafos atrás, siguiendo con el trabajo que ha hecho el Tribunal respecto de las normas constitucionales sobre tratados internacionales, para luego llegar al análisis específico de la jurisprudencia del Tribunal sobre cláusulas autoejecutables y no autoejecutables de los tratados internacionales, concluyendo con un análisis crítico de dicha jurisprudencia y de la distinción entre las referidas cláusulas en cuanto a los efectos de los tratados internacionales en su vigencia en el ordenamiento jurídico de Chile.

8 Arts. 32, n. ${ }^{\circ} 6,8$ y 15, y 54 n. ${ }^{\circ} 1 \mathrm{CP}$.

9 Art. 93 n. $^{\circ} 1 \mathrm{CP}$.

10 No está regulado literalmente en la Constitución, pero a partir de la teoría de las normas constitucionales adscritas podemos sostener que sí lo está, como lo señalaremos más adelante. 
II. LA JURISPRUDENCIA DEL TRIBUNAL CONSTITUCIONAL

SOBRE TRATADOS INTERNACIONALES

\section{El Tribunal Constitucional chileno y los tratados internacionales}

El Tribunal Constitucional inició su jurisprudencia sobre la materia en el Rol n. ${ }^{\circ} 46$, y desde entonces los tratados internacionales han ocupado gran parte del trabajo de esta magistratura, siendo común ver en los escritos de los recurrentes su invocación. En términos generales cabe señalar que el Tribunal ha sido conservador en su histórica línea jurisprudencial en torno a la relación derecho internacional-derecho interno, y en estos últimos años ha derivado en una jurisprudencia inestable que ha aumentado la incerteza jurídica a nivel constitucional, como ya se ha adelantado.

En esta óptica corresponde ocuparse de dos asuntos respecto de los tratados internacionales y su consideración por parte del Tribunal Constitucional en líneas generales: la primera referida al valor de los tratados internacionales como parámetro del control de constitucionalidad, en su categoría de fuente de los derechos fundamentales, y la segunda referida al estatuto propiamente tal de los tratados internacionales en el sistema constitucional chileno.

a. Los tratados internacionales como fuente de derechos fundamentales y su valor constitucional

A pesar de no ser el objeto de este trabajo el papel de los tratados internacionales como fuente de los derechos fundamentales y su respectiva jerarquía en el derecho constitucional, es vital conocer el desarrollo que ha realizado el Tribunal Constitucional pues permite una comprensión cabal del fenómeno y de cómo incidirá en el objeto de esta investigación.

La jurisdicción constitucional ha sido muy reacia a reconocer en los tratados una fuente directa del derecho constitucional chileno. Respecto de los tratados internacionales y su relación con el artículo 5. ${ }^{\circ}$ inciso $2 \mathrm{CP}$, ha sostenido de forma reiterada que el límite constitucional a la normativa infraconstitucional son los derechos esenciales que emanan de la naturaleza humana y no los tratados que los contienen.

En sentencia Rol n. ${ }^{\circ}$ 1340-09 construyó el derecho implícito a la identidad a través del artículo $5 .^{\circ}$ inciso $2 \mathrm{CP}$ y los tratados internacionales, pero en sentencia Rol n. ${ }^{\circ}$ 2105-11 renunció a construir derechos implícitos en virtud de tal razonamiento, optando por razonar a partir exclusivamente de los derechos del catálogo constitucional.

Se suma lo anterior a lo señalado en los roles acumulados 2387 y 2388 en su considerando duodécimo: "Que la sola lectura de las normas contenidas en el artículo $5 .^{\circ}$ inciso segundo, $32 \mathrm{n} .^{\circ} 17$ y 54 n. ${ }^{\circ} 1$, de la Constitución chilena, que se refieren a los tratados internacionales, es suficiente para 
concluir que nuestro texto fundamental no contiene una mención explícita al rango normativo de los tratados internacionales, ni siquiera cuando ellos versan sobre derechos esenciales que emanan de la naturaleza humana" ${ }^{11}$.

El desarrollo jurisprudencial sobre la materia continúa de forma aún más oscilante en los últimos años, en donde, en sentencias en sede de inaplicabilidad, por breves lapsos de tiempo sostiene criterios contradictorios: así, al pronunciarse sobre la inaplicabilidad del Decreto Ley de Extranjería 10.094, en sentencia Rol n. ${ }^{\circ} 2273$, el Tribunal rompe con sus criterios tradicionales; a la sazón describe el fallo la Dra. Galdámez en los siguientes términos:

... es un ave rara en los criterios a que nos viene acostumbrando el Tribunal Constitucional. Se trata, en mi opinión, de una sentencia excepcional por tres razones. En el tema que venimos estudiando desde hace unos años -el valor del Derecho Internacional de los Derechos Humanos en el ordenamiento interno- la sentencia confiere a los tratados ratificados y vigentes acá invocados el poder de actuar como un límite frente a los poderes del Estado, los analiza como parámetro del control de constitucionalidad y en base a estos tratados y la propia Constitución propone un estatuto jurídico mínimo para los extranjeros. Es algo de verdad infrecuente, porque el Tribunal viene señalando desde hace tiempo que en esta materia prima el principio de deferencia con el legislador ${ }^{12}$.

A los pocos meses, en otra acción de inaplicabilidad, resuelta en fallo Rol n. ${ }^{\circ} 2257$, en donde se impugnaba la constitucionalidad de iguales normas, el Tribunal descarta declarar la inaplicabilidad sobre la base de que las situaciones de hecho planteadas eran diferentes, y especialmente, por razones de admisibilidad. Así el Tribunal no consolidó la tendencia que planteó en el Rol n. ${ }^{\circ} 2273$, y sin señalar precisamente cuáles eran los supuestos de hecho que permitían arribar a una conclusión jurídica diferente.

Finalmente, en materia de justicia militar es donde el Tribunal Constitucional más ha abierto sus criterios en materia de tratados internacionales; así, en el Rol n. ${ }^{\circ} 2493$ sostiene:

NOVENO: Que, a la luz de tales antecedentes, no cabe duda [de] que la aplicación conjunta de los preceptos impugnados provoca una vulneración de los derechos a ser oído por un juez competente, a la publicidad del proceso y a ser juzgado por un tribunal independiente e imparcial, con transgresión de los preceptos contenidos en el artículo 8 de la Convención Americana sobre Derechos Humanos y en el artículo 19, n. $^{\circ} 3 .^{\circ}$, de la Constitución Política de la República;

11 Tribunal Constitucional de Chile, Roles acumulados n. ${ }^{\circ} 2387$ y n. ${ }^{\circ} 2388$, de 23 de enero de 2013.

12 GALDÁMEZ, 2013, 770. 
DÉCIMO: Que, asimismo, dicha aplicación infringe la exhortación al legislador en orden a adoptar medidas de protección a las víctimas, contenida en el artículo 83 de la Constitución, prescindiendo de las reglas sobre tutela del debido proceso;

DECIMOPRIMERO: Que, por ende, procede declarar inaplicables los preceptos tachados de inconstitucionales, en cuanto contravienen los artículos 19, numeral 3. ${ }^{\circ}$, inciso sexto, y 83 de la Constitución Política ${ }^{13}$.

Con lo ya expresado podemos concluir que para el Tribunal los tratados internacionales no son fuente directa de los derechos fundamentales, solo son tales los derechos esenciales que emanan de la naturaleza humana que ellos contengan ${ }^{14}$.

Asimismo el valor de dichos derechos -los contenidos en tratados- no es parámetro directo de inconstitucionalidad, debiendo estos ser anclados a la normativa constitucional respectiva ${ }^{15}$.

Finalmente, se puede apreciar en la actualidad una tendencia a la apertura a novedosas tendencias como el control de convencionalidad ${ }^{16}$, pero, dada la

13 Tribunal Constitucional de Chile, Rol n. ${ }^{\circ} 2493$, de 6 de mayo de 2014.

14 La Corte Suprema de Justicia también sigue la misma tesis: "como lo ha señalado esta misma Corte Suprema en reiteradas sentencias, de la historia fidedigna del establecimiento de la norma constitucional contenida en el artículo 5..$^{\circ}$ de la Carta Fundamental, queda claramente establecido que la soberanía interna del Estado de Chile reconoce su límite en los derechos que emanan de la naturaleza humana, valores que son superiores a toda norma que puedan disponer las autoridades del Estado, incluido el propio Poder Constituyente, lo que impide sean desconocidos": Corte Suprema, Rol n. ${ }^{\circ}$ 559-2004, de 13 de diciembre de 2006, considerando 22.

Cabe precisar que la doctrina de la justicia ordinaria, que ha sido más coherente y consistente que la del Tribunal Constitucional en la materia, ha utilizado directamente los tratados internacionales, en especial en casos de graves violaciones de derechos humanos, pero más que utilizarlos como parámetro de control de constitucionalidad, lo que hace es resolver cuestiones de aplicación de derecho interno o al mandato legal contenido en el artículo 68 de la Convención Americana de Derechos Humanos. Como insistiremos más adelante, los tratados internaciones en su vigencia interna tienen eficacia jurídica como ley de la República.

15 Sostiene fundadamente Galdámez: "hasta ahora los tratados internacionales sobre derechos humanos han actuado como un canon de integración e interpretación de los derechos fundamentales. En el primer caso se ha operado a través de los derechos implícitos que el TC ya ha reconocido en varias sentencias a propósito de la tutela judicial efectiva, del derecho a la propia imagen y derecho al nombre. En el segundo caso, el DIDH ha operado como un criterio que permite reforzar los argumentos. Por su parte, la Corte Suprema ha entendido que los principios del ius cogens internacional tienen aplicación en Chile, son normas imperativas y obligatorias.

"Los derechos esenciales que emanan de la naturaleza humana contenidos en esos tratados se incorporan a la Constitución material, son parte de ella y contribuyen a ampliar el catálogo de derechos cuando se reconocen derechos implícitos y también cuando se ensancha el sentido y alcance de los derechos constitucionales": GALDÁmEZ, 2014, 358-359.

16 Para mayores antecedentes sobre el control de convencionalidad véase ibíd., 337-346; YÁÑEZ, 2014a y YÁÑEZ, 2014b. 
inestable elaboración de la doctrina del Tribunal Constitucional, todo dependerá de los consensos que logre la magistratura en el futuro ${ }^{17}$.

b. El estatuto constitucional de los tratados internacionales según el Tribunal Constitucional

El Tribunal Constitucional ha establecido en su jurisprudencia dos cuestiones relevantes ${ }^{18}: 1$. El concepto de precepto legal y 2 . Que el derecho convencional internacional vigente en el orden jurídico interno son preceptos legales ${ }^{19}$ (a efectos del presente trabajo no importa la vigencia en el orden jurídico internacional, como aclararemos más adelante).

Siendo coherente en esa línea, el Tribunal, respecto del control represivo concreto de constitucionalidad, en Rol n. ${ }^{\circ} 1288$ (sede control obligatorio preventivo de constitucionalidad de leyes orgánico constitucionales) fundamentalmente:

- Señala que los tratados internacionales en cuanto a su vigencia interna se someten a la Constitución, son inferiores a esta ${ }^{20}$.

17 Como ha señalado Galdámez, "[1]a falta de unanimidad sobre el sentido y alcance del inciso segundo del artículo $5 .^{\circ}$ ha dado lugar a distintas interpretaciones en la doctrina y en la jurisprudencia de las máximas jurisdicciones": GALDÁmEZ, 2014, 333. Esa indefinición en la doctrina y la jurisprudencia ha provocado sendas contradicciones en la jurisprudencia del Tribunal a la hora de pronunciarse sobre la relación del derecho internacional de los derechos humanos, y su principal fuente, los tratados internacionales, con el derecho interno. Ello augura que mientras no exista una definición expresa del asunto por vía de reforma constitucional o nueva Constitución, se mantendrá la indefinición jurisprudencial en la materia. Cierta doctrina a inicios de la década de 2000 señalaba que sería la jurisdicción constitucional la encargada de dotar de un sentido claro a los supuestos vacíos normativos en materia de derecho internacional en la Constitución, pero luego de todo lo reseñado, es evidente que el Tribunal Constitucional claudicó ante dicha labor.

Respecto a las novedosas tendencias jurisprudenciales del Tribunal cabe recordar lo que se ha señalado y que es clarificador al respecto: "El TC chileno invoca, junto a diversas otras fuentes del Derecho, a la Convención Americana de Derechos Humanos pero no recurre con la misma intensidad a jurisprudencia de la Corte IDH, ni tampoco se refiere a las sentencias de tribunales constitucionales del entorno cuando interpretan dicha convención": GALDÁMEZ, 2012, 191.

Respecto a la discusión nacional sobre la posición normativa y su jerarquía dentro de nuestro ordenamiento, clarificador a fines de la década de 1990 es el volumen especialmente dedicado a la materia por la revista Ius et Praxis en 1997 (año 9, n. ${ }^{\circ}$ 1), el cual condensa la discusión de nuestra doctrina en ese entonces, y que no ha variado de manera significativa hasta el día de hoy.

18 La sentencia leading case en la materia por parte del Tribunal Constitucional es el Rol n. ${ }^{\circ} 346$ sobre el Estatuto de Roma que creó la Corte Penal Internacional.

19 A modo de ejemplo, roles n. $^{\circ} 288,309,312$ y 346, todos del Tribunal Constitucional. Ver en buscador de sentencias, en: www.tribunalconstitucional.cl.

20 Tribunal Constitucional de Chile, Rol n. ${ }^{\circ}$ 1288, de 25 de agosto de 2009, considerandos 41 y 43 . 
- Asimila parcialmente el tratado a la ley, y lo considera, desde su ubicación en el ordenamiento jurídico interno, como un precepto legal (pues regula materias de dominio legal) ${ }^{21}$.

- Afirma que el tratado internacional, por el mero acto de la ratificación, se incorpora al derecho interno, como precepto legal ${ }^{2223}$.

- Reconoce la regla de derecho internacional general constitucionalizada por el artículo 54.1 CP, que hace referencia al principio consagrado en el artículo 27 de la Convención de Viena sobre Derecho de los Tratados ${ }^{24}$.

- Decide, por tanto, que procede la declaratoria de inaplicabilidad, y que es inconstitucional la restricción por el legislador de las competencias constitucionales del Tribunal ${ }^{25}$.

Esta sentencia fue criticada por cierto sector de la doctrina internacionalista el cual principalmente señalaba que, al privar de efectos a un tratado internacional en el orden interno, este se suspendía, y por tanto con ello se contrariaba el artículo $54.1 \mathrm{CP}^{26}$.

Luego, el Tribunal Constitucional extrañamente cambia su criterio en el año 2015, en el Rol n. ${ }^{\circ} 2789$, pronunciándose en sala sobre la admisibilidad de un recurso de inaplicabilidad, donde, sin mayor razonamiento, señala:

... que una norma de un tratado internacional ratificado por Chile no constituye un precepto que tenga rango legal, en términos tales que pueda promoverse a su respecto una acción de inaplicabilidad (resaltado del autor).

Que la declaratoria de inaplicabilidad contraría los compromisos internacionales del Estado, refiriéndose al principio pacta sunt servanda consagrado en el artículo 27 de la Convención de Viena y en la propia Constitución en su artículo 54.1.

21 Ibíd., considerandos 43, 47 y 48.

22 Ibíd., considerando 53.

23 Se puede sostener, siguiendo la práctica jurisprudencial nacional y lo señalado por Aldunate y Llanos Mansilla, que el tratado produce efectos en el derecho interno desde su promulgación y publicación. Sin dichos requisitos el tratado internacional solo conserva su capacidad original de generar obligaciones en el orden jurídico internacional. Distinción que, como veremos, cobra gran relevancia y en la cual el Tribunal Constitucional no repara. LLANOS, 2011, 140-143. AldunATE, 2010, 185-210.

En la misma línea sostiene Jorge Tapia: "sólo cabe considerar vigentes aquellos tratados en que al menos el decreto supremo ratificatorio y promulgatorio ha sido totalmente tramitado y publicado": TAPIA (2003), 355.

24 Tribunal Constitucional de Chile, Rol n. ${ }^{\circ}$ 1288, 25 de agosto de 2009, considerandos 51,56 y 68 .

25 Ibíd., considerando 40.

26 Así Pica, criticando el Rol n. ${ }^{\circ} 1288$, sostiene: "pues ahora se declara de manera expresa en la Carta fundamental que nunca una ley o cualquier norma de derecho interno podrá modificar lo dispuesto en un tratado": PICA, 2012, 263. 
En este sentido, aparentemente tenemos dos líneas jurisprudenciales vigentes sobre el mismo asunto en la jurisprudencia del Tribunal Constitucional. Se utiliza la expresión "aparentemente" toda vez que la tesis sostenida en el Rol n. ${ }^{\circ} 2789$ es aislada y ha sido adoptada por una sala del Tribunal Constitucional y no por el pleno. De este modo cabe concluir que para el Tribunal las principales características de los tratados internacionales y su regulación constitucional son las ya señaladas en el Rol n. ${ }^{\circ} 1288$.

Con todo lo señalado hasta aquí ya tenemos un panorama general sobre las tesis sostenidas por la magistratura constitucional sobre los tratados internacionales y su vigencia en el orden jurídico interno ${ }^{27}$.

\section{Las cláusulas autoejecutables y no autoejecutables en el Tribunal Constitucional}

Procede ahora adentrarse en el objeto de esta investigación. Para una mayor claridad en la exposición del tema lo hemos desarrollado mediante el análisis particular de algunas sentencias emanadas del Tribunal Constitucional pronunciadas hasta la fecha.

a. Sentencia Rol n. 309

\section{Hechos:}

El caso se circunscribe a un requerimiento de inconstitucionalidad presentado por un grupo de congresistas ante el Tribunal Constitucional para que se pronuncie sobre una serie de cuestiones de constitucionalidad de forma y fondo planteadas en contra del Convenio n.$^{\circ} 169$ sobre Pueblos Indígenas y Tribales en Países Independientes de la Organización internacional del Trabajo (оIт) de 1989.

Consideraciones sobre la categoría de normas autoejecutables y no autoejecutables en un tratado:

El Tribunal Constitucional introduce en su jurisprudencia la categoría de normas autoejecutables y no autoejecutables de los tratados internacionales en su vigencia en el derecho interno, declarando que el derecho a la consulta establecido en el artículo 7 del Convenio n. 169 de la oIT es una norma

27 Uno de los evaluadores de este artículo mencionó como necesario pronunciarse sobre el papel del artículo $54 \mathrm{n} .^{\circ} 1$ inciso $5 \mathrm{CP}$ para comprender la profundidad de la problemática constitucional en la materia. Para evitar desarticular la estructura de este trabajo redirijo a un reciente comentario jurisprudencial de mi autoría publicado en Chile, trabajo donde estudio en mayor profundidad la discusión de la referida disposición constitucional y su relación con el artículo 27 de la Convención de Viena sobre el Derecho de los Tratados. Ver Yáñez, 2016, 155-161. 
autoejecutable, y por medio de un razonamiento interpretativo (sentencias interpretativas) concluye que dicha disposición es conforme a la Constitución ${ }^{28}$.

\section{b. Sentencia Rol n. ${ }^{\circ} 383$}

\section{Hechos:}

El caso se circunscribe a un requerimiento de inconstitucionalidad planteado por un grupo de congresistas ante el Tribunal Constitucional con el objeto de que se declare la inconstitucionalidad del proyecto de acuerdo que aprueba la Convención Interamericana sobre Desaparición Forzada de Personas, adoptada el 9 de junio de 1994 en Belén, Brasil, durante el XXIV Período Ordinario de Sesiones de la Asamblea General de la Organización de Estados Americanos, en atención a que la consagración que en ella se hace del principio de universalidad de la jurisdicción, establecido en su artículo IV, inciso segundo, vulnera el artículo $5 \mathrm{CP}$.

\section{Consideraciones sobre la categoría de normas autoejecutables/no autoeje- cutables de un tratado:}

La magistratura constitucional, por considerar que la norma cuestionada, a pesar de no ser autoejecutable, de no pronunciarse el Tribunal podría hacer

28 Sostiene el Tribunal Constitucional: “a) Los tratados, para su aplicación en el orden interno de un país, pueden contener dos tipos de cláusulas, denominadas por la doctrina 'self executing' y 'non self executing'.

"Las primeras, son las que tienen el contenido y precisión necesarias que las habilita para ser aplicadas sin otro trámite como fuente del derecho interno. En otros términos, son autosuficientes, y entran a la legislación nacional cuando el tratado que las contiene se incorpora al derecho vigente.

"Las segundas, son aquéllas que requieren para su entrada en vigencia de la dictación de leyes, reglamentos o decretos que las implementen y, en tal evento, las haga aplicables como fuente del derecho interno. En otras palabras, imponen la obligación al Estado, para que en uso de sus potestades públicas, sancione la normativa necesaria para que por esa vía les dé vigencia efectiva.

"Pueden existir tratados que sólo contengan cláusulas autoejecutables y otros que sólo contengan no ejecutables, como puede un mismo tratado contener unas y otras. Esta precisión resulta determinante para pronunciarse sobre la inconstitucionalidad de los preceptos del tratado, toda vez que aquellos cuyas normas o algunas de ellas requieran, para tener fuerza interna, de una actividad legislativa o administrativa posterior, no pueden, por esa razón, entrar en contradicción desde pronto con el ordenamiento constitucional ya que no son normas vigentes ni tampoco lo serán cuando el Presidente de la República ratifique el tratado si es que es aprobado por el Congreso y el Ejecutivo decide así hacerlo. Si los preceptos que se deben dictar para implementarlo, llegaren a contener disposiciones contrarias a la Constitución, ello será decidido en su oportunidad por los órganos de control de constitucionalidad que la propia Carta Fundamental establece.

"Siendo así, en cada caso particular deberá previamente decidirse por este Tribunal si las disposiciones del tratado son o no auto ejecutables y, por ende, si quedarán incorporadas, sin necesidad de otro acto de autoridad, al derecho interno. Sólo en el evento de que la norma sea autoejecutable, el Tribunal debe -en esta instancia jurisdiccional- pronunciarse sobre su constitucionalidad": Tribunal Constitucional de Chile, Rol n. 309,4 de agosto de 2000, considerando 48. 
incurrir al Estado en responsabilidad internacional en virtud del artículo 27 de la Convención de Viena sobre Derecho de los Tratados ${ }^{29}$, entra a analizar constitucionalidad de forma de la norma impugnada y la declara inconstitucional por no haber sido aprobada conforme a los quórums establecidos para ello, a saber, el de ley orgánica constitucional ${ }^{30}$.

c. Sentencia Rol n. ${ }^{\circ} 1050$

\section{Hechos:}

El Tribunal, en sede de control preventivo obligatorio de constitucionalidad de los tratados internacionales que versen sobre materias de leyes orgánico constitucionales, conoce sobre la constitucionalidad de los artículos $6 .^{\circ}, \mathrm{n}^{\circ} 1$, letra a), y n. ${ }^{\circ} 2$, y $7 .^{\circ}$, n. ${ }^{\circ} 1$, oración segunda, del Convenio n. ${ }^{\circ} 169$ de la огт.

\section{Consideraciones sobre la categoría de normas autoejecutables/no autoeje-} cutables de un tratado:

El Tribunal, con base en el razonamiento del Rol n. ${ }^{\circ} 309$, de forma implícita, consideró que estaba en presencia de normas asimilables a leyes orgánico constitucionales. Es decir, realizó control de constitucionalidad por estar frente a normas autoejecutables.

\section{d. Sentencia Rol n. ${ }^{\circ} 1483$}

\section{Hechos:}

En sede de control preventivo obligatorio de constitucionalidad de tratados internacionales que versen sobre materias de leyes orgánicas constitucionales, se pronuncia sobre la constitucionalidad del artículo 9 de la Convención

29 En nuestra opinión el Tribunal Constitucional hace una errada alusión al artículo 27, pues debería hacerla es al artículo 18 de la referida Convención.

30 "Cuarto: Que, por otra parte, la distinción efectuada por la ya citada sentencia de este Tribunal de 4 de agosto de 2000, Rol n. ${ }^{\circ} 309$, entre normas autoejecutables y no autoejecutables, debe ser precisada para una comprensión cabal de la jurisprudencia de esta Magistratura, siendo ésta la oportunidad de hacerlo. Tal doctrina, desde luego y naturalmente, tiene una excepción importante. Esta consiste en que si la norma no autoejecutable requiere de la aprobación por el Estado de Chile de preceptos que, conforme a la Constitución, conduzcan o puedan conducir a una inconstitucionalidad de fondo que afecte a la Convención, como podría ocurrir en la especie, no resulta aceptable ni razonable postergar una resolución sobre ella, habida consideración, en especial, de las disposiciones sobre cumplimiento de los tratados, con singular significación su artículo 27, contenidas en la Convención de Viena publicada en el Diario Oficial de 22 de junio de 1981. La excepción anotada cobra mayor fuerza si existe una jurisprudencia de este Tribunal que pudiera estimarse aplicable al caso en estudio, como acontece con la sentencia dictada el 8 de abril de 2002, Rol n. ${ }^{\circ} 346$ ". Tribunal Constitucional de Chile, Rol n. ${ }^{\circ} 383,5$ de septiembre de 2003 , considerando 4. 
Internacional para la protección de todas las personas contra las desapariciones forzadas.

Consideraciones sobre la categoría de normas autoejecutables/no autoejecutables de un tratado:

Reitera la categoría de normas autoejecutables y no autoejecutables establecida en el considerando 48 de la sentencia Rol n. ${ }^{\circ} 309$. Acto seguido el Tribunal considera que la disposición cuestionada no es de aquellas de carácter orgánico constitucional, teniendo presente la naturaleza no autoejecutable de la misma ${ }^{31}$.

e. La sentencia roles acumulados n. ${ }^{\circ} 2387$ y n..$^{\circ} 2388$ : un cambio de criterio

\section{Hechos:}

Un grupo de congresistas plantea una cuestión de constitucionalidad ante el Tribunal Constitucional, requiriendo la declaración de inconstitucionalidad de determinadas normas del proyecto de ley que "Modifica, en el ámbito de la sustentabilidad de recursos hidrobiológicos, acceso a la actividad pesquera industrial y artesanal y regulaciones para la investigación y fiscalización, la Ley General de Pesca y Acuicultura contenida en la ley n. ${ }^{\circ} 18.892$ y sus modificaciones".

Señala el Tribunal sintetizando los requerimientos:

31 “sÉptimo.- Que en el artículo noveno de la Convención en análisis se indica: '1. Cada Estado Parte dispondrá lo que sea necesario para instituir su jurisdicción sobre los delitos de desaparición forzada' en los casos que señala. '2. Cada Estado Parte tomará asimismo las medidas necesarias para establecer su jurisdicción sobre los delitos de desaparición forzada' en la situación que menciona (énfasis agregado);

"OCTAVO.- Que del tenor de la disposición se desprende que se trata de un precepto no autoejecutable, esto es, que impone a cada Estado Parte la obligación previa de hacer uso de su propia potestad pública para sancionar las normas que sean necesarias para darle a ésta efectiva vigencia.

"En consecuencia, por sí sola no le otorga jurisdicción alguna a ninguno de ellos, los cuales deben adecuar al efecto su propio ordenamiento jurídico interno con tal objeto;

"NOVENO.- Que, de este modo, el artículo noveno de la Convención en estudio no regula por sí mismo una materia que sea propia de la ley orgánica constitucional a que se refiere el artículo 77 de la Constitución Política y, por lo tanto, no le corresponde a esta Magistratura pronunciarse sobre dicho precepto;

"[...] DECIMOPRIMERO.- Que, sin perjuicio de lo anterior y en la misma forma como tuvo ocasión de indicarlo esta Magistratura en la sentencia de 4 de agosto de 2000 antes mencionada, si los preceptos legales que han de dictarse para implementar el artículo noveno del Tratado 'llegaren a contener disposiciones contrarias a la Constitución, ello será decidido en su oportunidad por los órganos de control de constitucionalidad que la propia Carta Fundamental establece' [Considerando cuadragesimoctavo, letra a)]". Tribunal Constitucional de Chile, Rol n. ${ }^{\circ} 1483,29$ de septiembre de 2009. 
c) El cuestionamiento central de inconstitucionalidad, que se configuraría por un vicio en la formación de la ley, al no haberse cumplido la norma autoejecutable sobre consulta previa prevista en el artículo $6 .^{\circ}$, y varias otras normas no autoejecutables o programáticas del Convenio 169 de la Organización Internacional del Trabajo, sobre Pueblos Indígenas y Tribales en Países Independientes, teniendo dicho Convenio rango constitucional, de acuerdo a lo previsto en el inciso segundo del artículo $5 .^{\circ}$ de la Constitución, considerando que se trata de un tratado sobre derechos humanos ${ }^{32}$.

Es decir, el requerimiento apunta a que, al ser las normas sobre el derecho a la consulta disposiciones autoejecutables del referido Convenio 169, y ser este un tratado de aquellos que integran la Constitución -insistimos, en opinión de los requirentes-, se habría infringido un trámite en la formación de la ley, de donde se seguiría su inconstitucionalidad.

\section{Consideraciones sobre la categoría de normas autoejecutables/no autoeje- cutables de un tratado: \\ El Tribunal señala que los tratados internacionales, incluidos los de derechos humanos, son inferiores a la Constitución y que el Convenio 169 de la OIT es ley de la República ${ }^{33}$. \\ Luego el Tribunal, en los considerandos siguientes, recuerda los criterios establecidos en los roles n..$^{\circ} 309$ y n..$^{\circ} 1050$, a saber, la autoejecutabilidad de}

32 Tribunal Constitucional de Chile, roles acumulados n. ${ }^{\circ} 2387$ y n. 2388,23 de enero de 2013, considerando 5 .

33 "undÉcImo: Que, en el ámbito del Derecho Internacional Público, existen diversas maneras de regular la recepción por el derecho interno de los Estados de las normas del derecho internacional convencional relativas a los derechos humanos, una de las cuales consiste en darles a tales normas internacionales convencionales jerarquía constitucional o, incluso, prevalencia sobre el derecho interno, mientras que, en otros casos, se les reconoce jerarquía superior a las leyes. Una última posibilidad es que el ordenamiento constitucional les confiera a los tratados internacionales el rango propio de una ley simple. [...]

"DUODÉCIMO: Que la sola lectura de las normas contenidas en los artículos $5 .^{\circ}$,inciso segundo, $32, \mathrm{n} .^{\circ} 17 .^{\circ}, \mathrm{y} 54, \mathrm{n} .^{\circ} 1$, de la Constitución chilena, que se refieren a los tratados internacionales, es suficiente para concluir que nuestro texto fundamental no contiene una mención explícita al rango normativo de los tratados internacionales, ni siquiera cuando éstos versan sobre derechos esenciales que emanan de la naturaleza humana.

"Con todo, de su contexto se infiere que los tratados internacionales tienen un rango inferior a la Constitución, porque están sometidos a control preventivo obligatorio de constitucionalidad cuando tratan materias de ley orgánica constitucional, conforme al artículo 93, inciso primero, n. ${ }^{\circ}$ 1, de la Carta Fundamental, lo que no sería posible si su valor fuere igual o superior a la Constitución misma. [...]

"DECimocuarto: Que esta Magistratura Constitucional cree útil recordar que el Convenio n. ${ }^{\circ} 169$ de la ort se incorporó al ordenamiento jurídico nacional como ley de la República al promulgarse, por Decreto Supremo n. ${ }^{\circ}$ 236, del Ministerio de Relaciones Exteriores, publicado en el Diario Oficial de 14 de octubre de 2008, luego de haber sido aprobado por el Congreso Nacional y haberse dado cumplimiento a la exigencia constitucional de control previo de su constitucionalidad por parte de este Tribunal" (resaltado del autor). Ibíd., considerandos 11, 12 y 14 . 
las normas referidas al derecho a la consulta en el Convenio 169 de la OIT. Pero, procede a dar una interpretación diferente para sus efectos, a propósito del caso sub lite ${ }^{34}$.

Así las cosas, el Tribunal Constitucional consideró que la norma que establece el derecho de consulta establecido en el señalado convenio es una norma autoejecutable, pero aun así requiere desarrollo legislativo, y que sólo en presencia de este se puede proceder a un control de constitucionalidad de forma, que pudiese plantear que la omisión de dicha consulta acarrease la omisión de un trámite legislativo, y por tanto, la referida inconstitucionalidad de forma.

\section{f. Síntesis}

De lo expuesto previamente podemos concluir que la doctrina del Tribunal Constitucional sobre cláusulas autoejecutables y no autoejecutables de tratados internacionales es del siguiente tenor:

- En el sistema jurídico chileno las normas de un tratado internacional vigente sólo pueden ser aplicadas por un juez conforme a la suficiencia normativa, a saber, si se encuentra ante una norma autoejecutable o no autoejecutable de un tratado.

34 "DECIMONOVENo: Que lo anterior resulta esencial de tener presente, pues si bien este mismo Tribunal, en sentencias recaídas en los roles N. 309 y 1050 , ha calificado al artículo $6 .^{\circ}$ del Convenio 169 de la orT, que consagra el derecho a la consulta de los pueblos indígenas, como una norma autoejecutable o self executing, ello debe conciliarse con la modalidad abierta con que están redactadas, en general, las normas de los tratados internacionales, lo que posibilita diversas interpretaciones de aplicación, en el derecho interno, de los parámetros conceptuales que ellas contienen. Este margen de discrecionalidad sobre la oportunidad y materia de la consulta puede ser perfectamente delimitado por la experiencia, guías y buenas prácticas que la Organización Internacional del Trabajo ha acumulado a lo largo de los años de vigencia del Convenio n. ${ }^{\circ} 169$. Así, por lo demás, se desprende del artículo 40 del Pacto Internacional de Derechos Civiles y Políticos y del artículo 2 del Pacto Internacional de Derechos Económicos, Sociales y Culturales $[\ldots]$

"VIGESIMOSEGUNDO: Que, transcurridos cuatro años desde la entrada en vigor del Convenio, la circunstancia de verse esta Magistratura en la necesidad de resolver nuevos requerimientos parlamentarios sobre esta materia, es demostrativa de la necesidad de que no se dilate, por parte del Congreso Nacional, regular apropiadamente este procedimiento de consulta. Junto a ello hay que indicar que el Congreso Nacional creó el 23 de Enero de 2013 la mencionada Comisión Bicameral con el objeto de poner en marcha toda la normativa que involucra el Convenio $n .{ }^{\circ}$ 169 de la oit;

"VIGESIMOTERCERO: Que, consecuentemente, la autoejecutividad de un tratado internacional no obsta al desarrollo legislativo del mismo sino que, por el contrario, lo impele. Es el legislador quien debe definir las autoridades u organismos representativos de las etnias originarias con derecho a participar en la consulta; la oportunidad y forma de participación en los procesos legislativos pertinentes, de modo libre, informado y no coaccionado, además de fijar el procedimiento. Sólo en esas condiciones este Tribunal Constitucional estará en situación de controlar si, efectivamente, se han creado condiciones de participación igualitarias para los pueblos indígenas, que equilibren sus oportunidades y propendan a un desarrollo equitativo": ibíd., considerandos 19, 22 y 23. 
- Sólo las normas autoejecutables de un tratado pueden ser sometidas al control preventivo obligatorio de constitucionalidad, pues de lo contrario no están vigentes en el ordenamiento jurídico, y por tanto no pueden producir efectos inconstitucionales.

- Lo anterior tiene una excepción, a saber, cuando el no examen de constitucionalidad de una norma no autoejecutable de un tratado pueda derivar en la afectación del objeto y fin del mismo en su vigencia en el orden jurídico internacional, conforme al artículo 18 de la Convención de Viena sobre el Derecho de los Tratados, generando responsabilidad internacional del Estado.

- Aun cuando una norma de un tratado internacional sea autoejecutable, esta puede requerir desarrollo legislativo, y por tanto no llegar a generar efectos jurídicos en el ordenamiento jurídico interno.

III. LAS CLÁUSULAS AUTOEJECUTABLES Y NO AUTOEJECUTABLES EN CHILE

\section{Conceptos y aclaraciones previas}

Sostiene Carlos Vásquez:

A distinction has become entrenched in United States law between treaties that are "self-executing" and those that are not. The precise nature of this distinctionindeed, its very existence-is a matter of some controversy and much confusion. More than one lower federal court has pronounced the distinction to be the "most confounding" in the United States law of treaties. A tremendous amount of scholarship has sought to clarify this distinction, but the honest observer cannot but agree with John Jackson's observation that "[t]he substantial volume of scholarly writing on this issue has not yet resolved the confusion" surrounding $i^{35}$.

Decidor es comenzar este análisis con dicha afirmación invocada por un profundo conocedor del derecho norteamericano, en donde se origina esta distinción. No nos proponemos resolver el asunto, nuestro interés es otorgar una aplicación coherente a los tratados internacionales suscritos, ratificados y publicados en el ordenamiento jurídico interno, así como corregir las prácticas que atentan contra la supremacía constitucional al considerar solamente objeto del control de constitucionalidad a las supuestas normas autoejecutables de tratados internacionales.

Paul de Visscher ${ }^{36}$ señala respecto al derecho convencional internacional que, en la mayoría de los Estados, el derecho constitucional no establece la adopción automática del tratado, sino que su integración en el derecho interno se realiza mediante un acto especial de recepción que, más que a las consi-

35 VÁsQueZ, 1995, 695.

36 Citado por PASTOR, 2003, 174. 
deraciones teóricas de las doctrinas dualistas, obedece a las exigencias de la técnica constitucional de la separación de poderes, y muy particularmente a las relaciones entre el poder ejecutivo y el poder judicial.

Planteada la cuestión anterior, sobre la que volveremos, cabe precisar por qué el Tribunal Constitucional acoge en su jurisprudencia esta categoría, y con unos efectos tan particulares, a saber, la imposibilidad de ejercer control de constitucionalidad preventivo frente a normas no autoejecutables de un tratado internacional, $\mathrm{y}$ ahora recientemente, frente a la presencia de normas autoejecutables, aún requerir desarrollo legislativo.

Así las cosas, cabe tener presente que la categoría de cláusulas self-executing y non self-executing es propia del sistema norteamericano de recepción del derecho convencional internacional. Así ha señalado la doctrina que, frente al artículo IV sección 2 de la Constitución de Estados Unidos,

... el derecho internacional fue aceptado como parte del derecho de los estados individuales, y después como parte del derecho federal, aparentemente, sin la necesidad de incorporación por el Congreso o por el presidente. Sin embargo, los tratados internacionales están sujetos al marco constitucional, y a nivel nacional prevalece una ley de los Estados Unidos posterior al tratado y tienen ampliamente desarrollada la doctrina de los acuerdos autoejecutivos, que establece que si a un tratado después de aprobación por el órgano legislativo ipso facto se le da estatus de ley interna, es un tratado autoejecutivo, a diferencia de los tratados que requieren un acto legislativo posterior a la ratificación, que son los acuerdos o tratados no autoejecutivos. En lo posible, un estatuto de los Estados Unidos se establece de tal manera que no entre en conflicto con el derecho internacional o con las obligaciones de los tratados. Los tratados internacionales y los acuerdos obligatorios para los Estados Unidos pueden ser interpretados y aplicados por sus $\operatorname{cortes}^{37}$.

Es decir, se trata de un sistema monista de recepción del derecho convencional internacional respecto de su situación como Estado federal ${ }^{38}$.

37 BECERRA, 2012, 36-37. Este autor continúa sus reflexiones señalando que, en el derecho constitucional estadounidense, para el poder judicial se sigue la postura del gobierno de turno, pues el Estado posee una sola voz, y esa es la del gobierno, y la de la legislación que dimana del Congreso, pudiendo una ley posterior prevalecer sobre un tratado vigente.

38 Señala Cornejo: "La doctrina de la autoejecutabilidad, o de la autoejecutividad de los tratados internacionales tuvo su origen en el derecho norteamericano. Fue la Corte Suprema de EE.UU. conociendo del asunto Foster v. Nielson, la que sostuvo, en su sentencia, que cuando los términos de una estipulación importan un contrato, cuando cualquiera de las partes se obliga a ejecutar un acto particular, el tratado se dirige al órgano político, no al judicial, y la legislatura debe ejecutar el tratado antes de que este pueda devenir en una regla para las cortes": CoRnEJo (s. d.).

Lambeth, a su turno, afirma sobe la discusión norteamericana: "El debate puede graficarse en torno a dos posiciones bien marcadas. Por una parte, el enfoque que podríamos denominar internacionalista, que sostiene que la interpretación correcta de la Cláusula Suprema en conjunto 
Es lógico que el sistema de recepción norteamericano del derecho convencional habilite a sus jueces a una aplicación razonable de este por medio de las categorías self executing y non self executing por la incorporación automática de los tratados internacionales al derecho de los estados federados. Ahora bien, ¿resultan razonables dichas categorías conforme a nuestro sistema constitucional de recepción de los tratados internacionales?

Para responder a esta interrogante es necesario volver a las categorías planteadas por Visscher. A pesar de la precaria regulación constitucional de los tratados internacionales en nuestra Constitución, podemos llegar a la convicción de que nuestro sistema no es de incorporación automática, como en los estados federados en Estados Unidos, sino uno de: recepción, previa ratificación o ejercicio de la potestad reglamentaria autónoma; promulgación, según sea el caso, y la necesaria publicidad, ya sea legal o administrativa, según corresponda. Así las cosas, nuestro sistema constitucional asume una posición dualista racional en los términos que sostenía Pastor Ridruejo. Ello por cuanto no es necesaria una ley de transposición del tratado; pero tampoco implica que con la mera ratificación o incluso con el mero ejercicio del Presidente de la República de sus facultades internacionales se entienda incorporado al derecho interno el tratado internacional ${ }^{39}$.

Esto deriva de la tradición constitucional chilena, integrada por la reiterada interpretación judicial y la sistematización de la doctrina. Es de recordar que Alexy ya ha planteado que el derecho positivo no sólo se constituye por normas jurídicas, sino que también por la interpretación reiterada y uniforme de los tribunales al crear nuevas reglas de derecho ${ }^{40}$.

Un tratado internacional en Chile sólo es aplicable por un juez nacional, previa incorporación al derecho interno, la que se produce por vía de su

con los fallos de la Corte Suprema supone entender que habría una presunción por el carácter self executing de los tratados internacionales. En tal sentido, los tratados internacionales serían directamente aplicables por las cortes y tribunales del país del mismo modo que lo sería una ley común y corriente o, incluso la propia Constitución (al menos en el sentido en que lo define en Marbury v. Madison).

"De otro lado, se encontrarían los así denominados nacionalistas, quienes afirman que una correcta interpretación de las fuentes lleva necesariamente a la conclusión de que habría una presunción de no autoejecutabilidad, que esa interpretación es respetuosa de la Cláusula Suprema y el rule of law y que las interpretación del Juez Marshall en Foster y Percheman son correctas si, y solo si, son leídas al modo que lo hace la Corte Suprema en el caso Medellín v. Texas.

"El debate tiene el elemento en común, donde lo que se discute es si los tratados internacionales son aplicables de acuerdo a la Cláusula Suprema contenida en el artículo VI de la Constitución de los EE.uv. Esta Cláusula es lo que se ha denominado el germen de la doctrina que permea todo el Derecho Constitucional norteamericano que afirma que la Constitución es la ley suprema de la nación, con la característica de anular cualquier ley que sea contraria y respecto de la cual, los tribunales deben imponerla". LAMBERTH, 2015, 46-47.

39 Incluso al ratificar tratados internacionales en virtud de lo que conocemos como potestad reglamentaria autónoma, se requiere la publicación. Arts. 32 n. ${ }^{\circ} 6$ y 54 n. ${ }^{\circ} 1 \mathrm{CP}$.

40 Alexy, 2000. 
aprobación inequívoca por parte del Congreso Nacional, la ratificación del mismo por el Presidente de la República, su promulgación que manda cumplir como ley de la República, y su publicación en el Diario Oficial ${ }^{41}$.

Verdugo y Pfeffer sostienen que "[1]a promulgación tiene sólo importancia para su validez interna, sirve para certificar la regularidad de su conclusión y ordena su ejecución dentro del territorio nacional" ${ }^{12}$, agregando a dicho planteamiento que "[s]i un convenio no es publicado carece de obligatoriedad interna y no puede ser aplicado por los tribunales de justicia, sin perjuicio, obviamente, de su validez y aplicabilidad en el plano internacional" ${ }^{43}$. Y precisan que para la promulgación y publicación de un tratado no pueden aplicarse los plazos legales y constitucionales ${ }^{44}$, mas en nuestra opinión sostenemos que de una acertada y coherente interpretación constitucional, que desde el cumplimiento de todos los procedimientos para la vigencia internacional de un tratado, se hace exigible al Presidente de la República el cumplimiento de los referidos plazos, pues la voluntad expresada por el Congreso Nacional ha sido esa ${ }^{45}$.

\section{Procedencia de la distinción en nuestro sistema jurídico de las categorías autoejecutable/no autoejecutable del derecho convencional internacional en su vigencia en el derecho interno}

Ya hemos revisado un marco teórico y normativo, y por supuesto, la postura del Tribunal Constitucional sobre la categoría de las cláusulas autoejecutables y no autoejecutables en nuestro sistema jurídico. Ahora corresponde

41 Sostiene Aldunate: "para su vigencia en el ordenamiento nacional, la publicación del tratado, ya sea de acuerdo a la fórmula que señala el código civil, ya sea de acuerdo a la Ley n. ${ }^{\circ}$ 18.158, que autoriza una forma especial de publicación de tratados de gran extensión, mediante el depósito de ejemplares autenticados en el Ministerio de Relaciones Exteriores y en la Contraloría General de la República, y el deber de ésta de mantener un ejemplar en cada una de sus oficinas regionales". AldunATe, 2010, 187.

Como dato a tener presente, la referida ley se aparta de criterios sostenidos en otros Estados, como en el sistema español, donde es exigencia publicar de forma íntegra el tratado, tal como manda el artículo 96 CE conjuntamente con el artículo 1.5 CC.

42 Verdugo, PfFefer y Nogueira, 1997, 79.

43 Ibíd.

44 Ibíd., 81.

45 En una postura similar, pero que no podemos compartir, Silva: "a nuestro juicio, deben entenderse como tratados vigentes, todos aquellos ratificados por nuestro país, y que mantengan ese vigor según el derecho internacional, aún cuando no se hayan cumplido respecto de ellos los trámites internos de promulgación y publicación. Estos trámites deberán, sin embargo, disponerse cuanto antes como consecuencia del deber constitucional del Estado, tal como por su lado, los particulares afectados por el incumplimiento de esas formalidades y la sociedad en general quedan, a nuestro juicio, habilitados para requerir la ejecución de tales formalidades y hacer efectivas consiguientemente de inmediato, las responsabilidades de toda especie proveniente de la infracción y atropello del ordenamiento jurídico chileno". SiLVA, 1977, 16. 
analizar si el desarrollo que ha hecho el Tribunal es el adecuado, frente a lo cual adelantamos una respuesta negativa.

Se agrupará en dos perspectivas el rechazo a la doctrina del Tribunal Constitucional, la primera desde el ejercicio del control preventivo de constitucionalidad de los tratados internacionales, y una segunda desde la vigencia interna del tratado internacional.

a. Las implicaciones de la doctrina de las cláusulas autoejecutables/no autoejecutables de los tratados internacionales en el control preventivo de constitucionalidad: su improcedencia

Desde la sentencia Rol n. 309 la magistratura constitucional concibe que aquellas cláusulas de tratados internacionales que no son autoejecutables por no incorporarse al ordenamiento jurídico chileno, no corresponde que sean objeto del control preventivo de constitucionalidad ejercido por el Tribunal. Dicha tesis es totalmente insostenible, en primer lugar, por contradecir la propia jurisprudencia del Tribunal acerca de la supremacía constitucional sobre los tratados establecida en la sentencia Rol n. ${ }^{\circ} 346$. Y en segundo lugar, por no ajustarse al régimen de recepción de los tratados, pues una vez publicados, se cumplirán como ley de la República (volveremos sobre esto en el acápite siguiente), donde no quedará margen para que el juez del fondo califique disposiciones aisladas de un tratado como autoejecutables o no autoejecutables, pudiendo por medio de su aplicación producir efectos inconstitucionales - ergo, reiteramos, se contradice el criterio de supremacía constitucional- ${ }^{46}$.

Sobre el punto se destaca, en lo que corresponde, lo sostenido por Miguel Fernández:

... no me parece coherente con el tipo de control que realiza el Tribunal Constitucional, que es de carácter abstracto, sostener que no pueda examinar, desde luego, el respeto del principio de supremacía por las disposiciones programáticas de un tratado. Es más, si el tratado fue sometido al Tribunal Constitucional y éste no efectuó pronunciamiento alguno en torno a aquellas disposiciones, sobre la base de la razón señalada, se corre el riesgo [de] que, después, cuando se intente la inconstitucionalidad del precepto legal o administrativo que las trate de ejecutar, se acuda, v. gr., a la Teoría de la Ley Pantalla, para terminar de esta manera, eludiendo el control de constitucionalidad ${ }^{47}$.

46 En nuestro derecho los jueces tienen el deber de aplicar la ley so pena de cometer el delito de prevaricación. No valiendo lo señalado por Thomas Buergenthal para ciertos modelos dualistas, pues los tratados incorporados al derecho nacional, conforme a lo ya reiteradamente señalado, se cumplen con fuerza de ley. Buergenthal, 1992, 293.

47 FERNÁNDEZ, 2003, 509. 
Por lo tanto, debiera el Tribunal Constitucional enmendar su doctrina jurisprudencial en la materia.

b. La vigencia en el ordenamiento jurídico interno de un tratado internacional y la improcedencia de la distinción entre cláusulas autoejecutables y no autoejecutables

El sistema constitucional chileno no admite una comparación con el sistema de recepción de tratados internacionales en Estados Unidos. Es inadmisible importar la categoría de self-excecuting y non self-executing treaties, y esto por dos grandes razones: la primera es que nuestro derecho constitucional consagra un dualismo racional en cuanto a la incorporación de los tratados internacionales a nuestro derecho interno, puesto que es necesario un acto de voluntad expreso y conforme a las normas constitucionales ${ }^{48}$ para la recepción del tratado en todo el territorio nacional; y la segunda es que el anterior acto de recepción manda a cumplir por los operadores jurídicos dicho tratado, al menos, con la fuerza normativa de ley de la República ${ }^{49}$. Ambos razonamientos se encuentran expresamente consagrados en la jurisprudencia del Tribunal, con algunas inconsistencias ${ }^{50}$, como anotásemos, pero en lo esencial el propio Tribunal lo ha establecido.

Hasta aquí hemos desarrollado una argumentación que nos permite comprender que para el ordenamiento jurídico chileno es imposible generar categorías de este tipo, los tratados para el operador jurídico, al menos se cumplen con la fuerza normativa de una ley de la República sin matizaciones. Por ello debemos asumir en serio la utilización de los tratados internacionales ante la jurisdicción, ya sean de derechos humanos u otros.

48 Véase el art. 46 de la Convención de Viena sobre el Derecho de los Tratados.

49 En este trabajo importa la consideración de la fuerza normativa de los tratados internacionales en el ámbito interno, no así su jerarquía o posición normativa. Para estas precisiones, en general, nos remitimos al excelente trabajo de Aldunate, quien sobre el particular considera: "En cuanto a su función normativa, debe destacarse la doble vinculación bajo la cual se encuentra el juez frente al tratado que si bien adquiere carácter de fuente interna, siempre conserva su carácter vinculante para el juez en cuanto órgano del estado obligado. De esto se desprende, en primer lugar, un cuestionamiento respecto de la doctrina que distingue entre cláusulas autoejecutables y no autoejecutables a la luz de disposiciones del tratado; la posibilidad de aplicar o no las cláusulas convencionales depende de la configuración del sistema de fuentes en su conjunto, y de las facultades del órgano jurisdiccional, y no de una apreciación aislada de las disposiciones del tratado". AldunAte, 2010, 209. Respecto de lo aquí señalado por Aldunate, tomamos distancia del criterio de la doble vinculación del juez del fondo, pues ello confunde criterios propios del derecho internacional público.

50 Como no considerar el requisito de publicación para la vigencia interna de los tratados o sólo considerar la ratificación para la misma circunstancia. Ambas situaciones se alejan de la tradición constitucional de Chile y de la adecuada inteligencia de las normas constitucionales sobre tratados internacionales. 
Es respecto de los tratados internacionales que consagran derechos humanos, que se plantean los principales problemas; ya sea por desconocimiento o por dolosa negligencia, se intenta, a partir de la eterna discusión sobre la jerarquía de los tratados, y ahora en torno a la categoría en estudio, privarlos de fuerza normativa en el derecho interno chileno ${ }^{51}{ }^{52}$.

Todos los tratados para el juez del fondo, para el Estado administrador y para el Congreso Nacional tienen valor de ley, y su cumplimiento es obligatorio en el ordenamiento interno una vez ratificados, promulgados y publicados.

Luego de publicado un tratado internacional y vigente en el orden jurídico interno, ¿por qué el Presidente de la República no podría ejercer la potestad reglamentaria autónoma para colmar las insuficiencias normativas de este? Claro que puede; y, es más, si consideramos un adecuado engranaje entre responsabilidad internacional del Estado y cumplimiento de la voluntad normativa expresada por el Congreso en el acto de aprobación, evidentemente es procedente. Más aún, si el Presidente de la República puede suscribir, ratificar, promulgar y publicar tratados internacionales que versen sobre otros tratados aprobados por el Congreso Nacional para velar por su debida ejecución, por qué no podría ejercer la potestad reglamentaria autónoma en el caso que hemos planteado. Claro está, siempre respetando la reserva legal establecida en el artículo $63 \mathrm{CP}^{53}$.

Finalmente, como ya ha señalado la Dra. Galdámez, la última posición manifestada por la magistratura constitucional, respecto de que aun frente a normas autoejecutables de tratados podríamos estar ante normas que requieran desarrollo legislativo, no resiste mayor análisis luego de lo planteado hasta aquí ${ }^{4}$.

51 Refiriéndose a los efectos del artículo 5 inciso 2 CP se ha, en nuestra opinión, erróneamente señalado: "Cabe en todo caso prevenir, que la plena eficacia de la norma internacional que asegura un derecho esencial para poder reclamar su aplicación directa por el órgano estatal correspondiente, exige que aquel se halle allí configurado con acabada precisión": Pfefrer, 2003, 478.

52 Para la aplicación de tratados bilaterales sobre protección de inversiones véase MonTT, 2005.

53 Buergenthal incluso sostiene que en los Estados donde se admite la distinción de tratados autoejecutables y no autoejecutables aun pueden ser fuente de derecho las cláusulas no autoejecutables para autorizar al poder ejecutivo o legislativo a dictar normativas complementarias que aseguren su ejecutabilidad/aplicabilidad. BuERGENTHAL, 1992, 293.

54 Respecto de la sentencia roles acumulados n. ${ }^{\circ} 2387$ y n. ${ }^{\circ} 2388$ del Tribunal Constitucional, Galdámez sostiene con meridiana claridad que el concepto de autoejecutable se vacía de contenido en dicha sentencia. Asimismo, sobre el punto de la potestad reglamentaria autónoma y refiriendo al mismo caso indica: "Este es otro de los problemas que plantea la sentencia, el Tribunal dice y es correcto, que el legislador no se ha pronunciado en esta materia, pero sí lo había hecho el Ejecutivo para proveer un instrumento que provisionalmente regulara el derecho a la consulta. Habría sido valioso que el Tribunal Constitucional explicara la razón para considerar que estaba ante una omisión del legislador que no podía ser colmado por el Ejecutivo, deberíamos concluir que estamos ante una materia propia del dominio legal": GALDÁmEZ, 2013, 631. 


\section{CONCLUSIONES}

Frente a lo razonado con anterioridad, se puede concluir cuanto sigue:

1. El Tribunal Constitucional ha importado desde el derecho comparado una categoría normativa según la cual, frente a normas de tratados internacionales que pudiesen calificarse como no autoejecutables, no procede el control preventivo de constitucionalidad.

2. El Tribunal Constitucional ha sostenido que frente a normas autoejecutables puede ser necesaria regulación legislativa para producir efectos jurídicos.

3. Las tesis anteriores son incompatibles con el sistema constitucional de recepción del derecho internacional convencional en Chile, el cual es de carácter dualista racional e impone la fuerza normativa de los tratados en el ámbito interno con valor, al menos, de ley de la República.

4. Para el operador jurídico nacional un tratado internacional ratificado, promulgado y publicado de acuerdo con el derecho constitucional es de obligatorio cumplimiento, conforme a la fuerza normativa precedentemente señalada.

5. El Presidente de la República, frente a insuficiencias normativas de un tratado, debe ejercer la potestad reglamentaria autónoma, o en su defecto, como colegislador, promover un proyecto de ley al respecto, con tal de no vulnerar cuando corresponda la reserva legal.

6. La doctrina nacional que invoca la mera validez del derecho convencional internacional en el ámbito de las obligaciones internacionales para invocar autoejecutividad de sus disposiciones en nuestro ordenamiento, yerra el análisis. El asunto, como hemos visto, es el de la determinación de la acertada interpretación de nuestro derecho interno, y el de establecer la aplicabilidad de las normas de los tratados internacionales a partir de su fuerza de ley en el derecho nacional como regla general a partir del cumplimiento del trinomio: ratificación, promulgación, publicación.

\section{REFERENCIAS}

Aldunate, E. (2010). La posición de los tratados internacionales en el sistema de fuentes del ordenamiento jurídico chileno a la luz del derecho positivo. Ius et Praxis, año 16, n. ${ }^{\circ} 2$.

Alexy, R. (2000). Derecho injusto, retroactividad y principio de legalidad penal. Doxa, n. ${ }^{\circ} 23$.

BeCERra, M. (2012). La recepción del derecho internacional en el derecho interno (2. ed.). México: Unam.

Buergenthal, T. (1992). Tratados auto-ejecutables y no auto-ejecutables en el derecho nacional y el derecho internacional (s. d.).

Connejo, F. (s. d.). Normas autoejecutables en tratados internacionales, disponible en: http:// www.tesis.uchile.cl/tesis/uchile/2004/cornejo_f/html/index-frames.html (Visitado el 05/05/2016). 
FERnÁndez, M.(2003). Visión prospectiva en relación con la regulación constitucional de los tratados internacionales. Ius et Praxis, año 9, n. ${ }^{\circ} 1$.

Fuentes, X. (2007). El derecho internacional y el derecho interno: definitivamente una pareja dispareja. Revista de Economía y Derecho, vol. 15, n. ${ }^{\circ} 4$.

Galdámez, L. (2012). El uso del derecho y jurisprudencia extranjera en los fallos del Tribunal Constitucional de Chile: 2006-2010. Revista Chilena de Derecho, vol. 39, n. ${ }^{\circ} 1$.

GALDÁmez, L. (2013). Comentario jurisprudencial: la consulta a los pueblos indígenas en la sentencia del Tribunal Constitucional sobre ley de pesca roles números 2387-12 CPT y 2388-12 CPт, acumulados. Estudios Constitucionales, año 11, n. ${ }^{\circ} 1$.

GAldÁmEZ, L. (2014). El valor asignado por la Jurisprudencia del Tribunal Constitucional a la jurisprudencia de la Corte Interamericana de Derechos Humanos. Estudios Constitucionales, año 12, n. $^{\circ} 1$.

Henríquez, M. (2009). Las fuentes formales del derecho. Santiago de Chile: Legal Publishing Chile.

LAmberth, G. (2015). Consideraciones para un tratamiento de las categorías de autoejecutabilidad y no-autoejecutabilidad de las normas de los tratados internacionales. Revista de Derecho Escuela de Postgrado, n. ${ }^{\circ} 7$.

Llanos, H. (2011). Teoría y práctica del derecho internacional público. Tomo Iv. Santiago: Jurídica de Chile.

Medina, C.(1996). El derecho internacional de los derechos humanos. En Medina, C. y Mera, J., eds. Sistema jurídico y derechos humanos. Santiago de Chile: Escuela de Derecho Universidad Diego Portales.

Montt, S. (2005). Aplicación de los tratados bilaterales de protección de inversiones por tribunales chilenos. Responsabilidad del Estado y expropiaciones regulatorias en un mundo crecientemente globalizado. Revista Chilena de Derecho, vol. 32, n. ${ }^{\circ} 1$.

PAstor, J. (2003). Curso de derecho internacional público y organizaciones internacionales (9. ${ }^{\text {a }}$ ed.). Madrid: Tecnos.

Pfeffer, E. (2003). Los tratados internacionales sobre derechos humanos y su ubicación en el orden normativo interno. Ius et Praxis, año 9, n. ${ }^{\circ} 1$.

PICA, R. (2012). Control de constitucionalidad y tratados internacionales: ¿objeto o parámetro? Una síntesis jurisprudencial del Tribunal Constitucional de Chile. En Nogueira, H., coord. El diálogo transjudicial de los tribunales constitucionales entre sí y con las cortes internacionales de derechos humanos. Santiago de Chile: Librotecnia.

Silva, A. (1977). Tratado de derecho constitucional. Tomo Iv. Santiago de Chile: Jurídica de Chile.

TAPIA, J. (2003). Efectos de los tratados sobre derechos humanos en la jerarquía del orden jurídico y en la distribución de competencias. Alcances del nuevo artículo 5. ${ }^{\circ}$ de la CPR de 1980. Ius et Praxis, año 9, n. ${ }^{\circ} 1$. 
VARgas, C. (2011). La función creadora del Tribunal Constitucional. Revista de Derecho Penal y Criminología, vol. XxxII, n. 92.

VÁsquez, C. (1995). The four doctrines of self-executing treaties. Georgetown Public Law and Legal Theory Research Paper, n. ${ }^{\circ}$ 12-101.

Verdugo, M.; Pffefer, E. y Nogueira, H. (1997). Derecho Constitucional. Tomo II. Santiago de Chile: Jurídica de Chile.

YÁÑEZ, M. (2014a). El control de convencionalidad en la jurisprudencia de la Corte Interamericana de Derechos Humanos. Problemas y desafíos. Estudios Jurídicos Democracia y Justicia, año 3 , n. ${ }^{\circ} 3$.

YÁÑEZ, M.(2014b). El control de convencionalidad en el Sistema Interamericano de Derechos Humanos. Concepto, influencias y proyecciones. Estado, participación y sociedad. Santiago de Chile: Legalpublishing.

YÁÑEz, M. (2016). El control de constitucionalidad represivo concreto de los tratados internacionales como fuente del derecho interno: una visión crítica de los roles 1288 y 2789 del Tribunal Constitucional de Chile. Tribuna Internacional, vol. 5 , n. ${ }^{\circ} 9$.

ZÚÑIgA, F. (2006). Sentencias del Tribunal Constitucional y el poder judicial. El valor del precedente. Estudios Constitucionales, año 4, n. ${ }^{\circ} 1$.

\section{Jurisprudencia citada}

Corte Suprema. Rol n. ${ }^{\circ}$ 559-2004, 13 de diciembre de 2006.

Tribunal Constitucional de Chile. Rol n. ${ }^{\circ}$ 309, 4 de agosto de 2000.

Tribunal Constitucional de Chile. Rol n. ${ }^{\circ}$ 383, 5 de septiembre de 2003.

Tribunal Constitucional de Chile. Rol n. ${ }^{\circ}$ 1288, 25 de agosto de 2009.

Tribunal Constitucional de Chile. Rol n. ${ }^{\circ}$ 1483, 29 de septiembre de 2009.

Tribunal Constitucional de Chile. Roles acumulados n. ${ }^{\circ} 2387$ y n. ${ }^{\circ} 2388,23$ de enero de 2013.

Tribunal Constitucional de Chile. Rol n. ${ }^{\circ}$ 2493, 6 de mayo de 2014.

Tribunal Constitucional de Chile. Rol n. ${ }^{\circ}$ 2789, 25 de marzo de 2015. 